AperTO - Archivio Istituzionale Open Access dell'Università di Torino

\title{
Grandparenting and Childbearing in the Extended Family
}

\section{This is the author's manuscript}

Original Citation:

Availability:

This version is available http://hdl.handle.net/2318/121415

since

Published version:

DOI:10.1007/s10680-012-9273-2

Terms of use:

Open Access

Anyone can freely access the full text of works made available as "Open Access". Works made available under a Creative Commons license can be used according to the terms and conditions of said license. Use of all other works requires consent of the right holder (author or publisher) if not exempted from copyright protection by the applicable law. 


\section{(3) \\ UNIVERSITÀ DEGLI STUDI DI TORINO}

This is an author version of the contribution published on:

Grandparenting and Childbearing in the Extended Family

(A. Aassve, E. Meroni, C. Pronzato)

European Journal of Population (2012) 28:499-518

(DOI 10.1007/s10680-012-9273-2)

The definitive version is available at:

http://link.springer.com/article/10.1007\%2Fs10680-012-9273-2 


\title{
Grandparenting and childbearing in the extended family
}

\author{
Arnstein Aassve \\ Department of Decision Science and \\ Carlo F. Dondena Centre for Research on Social Dynamics \\ Università Bocconi, via Guglielmo Röntgen 1, 20136 Milan,Italy \\ arnstein.aassve@unibocconi.it \\ Elena Meroni \\ Department of Statistical Sciences, University of Padua, \\ Via C.Battisti 241, Padova, Italy; \\ and \\ Carlo F. Dondena Centre for Research on Social Dynamics \\ Università Bocconi, via Guglielmo Röntgen 1, 20136 Milan,Italy \\ elena.meroni@stat.unipd.it \\ Chiara Pronzato \\ Carlo F. Dondena Centre for Research on Social Dynamics \\ Università Bocconi, via Guglielmo Röntgen 1, 20136 Milan,Italy \\ CHILD Collegio Carlo Alberto \\ chiara.pronzato@unibocconi.it
}

\begin{abstract}
The paper analyses the impact of grandparenting on individuals' fertility behaviour using longitudinal data from eleven European countries. In particular, we focus on how siblings may share and compete for grandparents' time in terms of childcare. By considering different family scenarios, we show that availability of grandparenting play an important role in individuals' decision making for having children. Grandparenting is particularly important in the South of Europe where public childcare is limited and here we see a large impact of grandparenting on fertility.
\end{abstract}

\section{Keywords}

fertility, grandparents, SHARE, extended family 


\section{Introduction}

There is extensive evidence of intergenerational transmission in demographic behaviour including childbearing and family formation (Knudsen and Murphy 2002). At the same time, the sociology literature documents substantial intergenerational support taking place in the form of both financial and in kind transfers. Although the amount of transfers varies across societies, the literature suggests a net downward transfer from the older to the younger generation. In this paper, we analyse grandparenting as a form of downward transfer and our interest lies in whether and how it might affect demographic behaviour in terms of childbearing. The basic argument is that availability of grandparents willing to undertake childcare should make the venture of childbearing easier, and hence have a positive effect on fertility. However, the mechanism is complex. The availability of grandparenting will depend on grandparents' characteristics, such as their age and health - let alone still being alive. Ill and frail grandparents might offer their availability but perhaps not considered as a very reliable form of childcare. Younger grandparents may be less available because they are still in gainful employment. Interestingly, the extent to which grandparents can offer their services will depend on their own past fertility behaviour. That is, if they postponed the onset of their own childbearing, there is likely to be a larger age gap between the generations and, assuming their children follow the trend of postponement, the grandparents might be too old to provide childcare for their grandchildren. Following this line of argument, the number (and age) of children the grandparents have will also matter. In other words, for an adult child, having siblings might make availability scarce if the grandparents already provide childcare to the children of the siblings. This implies that the more siblings (and the more children they have) the lower the chance of an adult child receiving assistance with childcare from their parents (i.e., the children's grandparents).

Importantly, the role of grandparenting varies across societies. For instance, grandparenting plays an important role in those countries where state welfare support is weak - the prime example being the Mediterranean countries. In countries where care activities are largely outsourced through public childcare and public care for the elderly, the role of grandparenting might be lower - or at least less important. However, the evidence is mixed. For instance, recent studies report strong and positive effect of grandparenting on a mother's decision to work (Del Boca, 2002; Arpino et al., 2010; Aassve et al., 2011; Hagestad, 2006) also for those countries where grandparenting is less prevalent. The key argument is that grandparents play an important role in helping out their adult children if in need. In other words, grandparenting might be less extensive, but it does nevertheless matter for those few that may not have good access to public childcare or who suffers from other sources of family stress.

The primary aim of the paper is to enhance our understanding of grandparents as a resource in the extended family. Our analysis relates to the literature that considers the impact of availability of formal childcare on fertility (Lehrer and Kawasaki, 1985; Del Boca, 2002; Andersson et al., 2004; Rindfuss et al., 2007; Rindfuss et al., 2010), but the issue of grandparenting differs in important ways. Among siblings, this resource is shared and characterized by family specific constraints for which the adult children may compete. Whereas the economic and demographic literature suggests that grandparental support will have important effects on adult children's decision-making, it is rarely observed in the data and as a result its possible effects on the adult children are - at least empirically - often ignored. Despite the vast literature, very few empirical studies make use of information on 
nuclear households that are clustered in an "extended family", the term we adopt in this paper to refer to three generations: grandparents, their adult children, and their grandchildren ${ }^{1}$.

In order to observe, at the same time, grandparents, their adult children, their grandchildren, and "care” relationships between them, we use data from SHARE (Survey of Health, Ageing and Retirement in Europe), a panel study which involves people aged 50+, in several European countries, which is available for the years 2004 and 2006. Those sampled are asked about their parents, their children, and their grandchildren, enabling us to observe potentially four generations at the same time. Instead of using the respondents as the unit of observation, we focus on their children. We can observe the fertility behaviour of the respondent's children over time (albeit the short period between the two waves). Our sample of adult children therefore includes siblings (all the children of each respondent) and their fertility behaviour, as well as their fertility history. Moreover, we have information about the extent to which grandparents provide childcare support for their adult children (i.e., care they provide to their grandchildren). From this information, we are able to answer four questions. 1) Is the helped adult child more likely to have another child? 2) And the contrary: will the adult child be less likely to have another child if not helped by the grandparents? 3) Do these effects depend on the age of the child that the grandparents are looking after? 4) To what extent might these effects differ across countries that provide rather different systems of support for families with young children?

In the methodological framework, each adult child observes his or her own parents' behaviour and we assume they form expectations about being helped in childcare. We theorize that the availability of grandparents in helping in childcare activities depends on three factors: 1) their availability and willingness to help: some grandparents may be too old or sick, may live far away, or may not want to sacrifice their leisure time; 2) time constraints: they may not to be able to look after more grandchildren from different adult children's families; and 3) energy constraints: grandparents may not be able to look after more grandchildren from the same adult child (especially if the youngest one is very young). We test whether grandparenting influences the fertility behaviours of their adult children by analyzing several sub-samples which represent different extended family scenarios. Results are interpreted in terms of availability, time, and energy constraints.

Our results show that being helped by grandparents increases the chance of having another child only when the existing grandchildren are older than three. The result is confirmed by the opposite evidence: the probability of having a(nother) child is lower when grandparents are already looking after a sibling's young children (under four years old). However, the probability is higher when the sibling's children are older, suggesting that grandparents helpin-turn their adult children. These results differ across North and South of Europe: in Southern European countries, where availability of formal care is limited, grandparenting plays a more important role

The findings have important policy relevance. If childcare by grandparents is preferred over formal childcare, this may suggest that families are in need of high quality childcare that is cheap and flexible, which essentially characterize grandparenting. In some countries, grandparenting is actively pursued as the main means of childcare. Grandparenting support schemes might work in so far as individuals do not have many siblings competing for their parents' help with their children, but our findings suggest that grandparenting is not sufficient

\footnotetext{
${ }^{1}$ In the sense that we use it, the members of an extended family need not be living in the same household.
} 
if individuals have several siblings, simply because grandparents are not able to look after several grandchildren at the same time.

The rest of the paper is organized as follows. Section 2 summarizes the relevant literature; Section 3 gives information about the survey, the construction of the dataset and the definition of the variables while Section 4 presents the applied empirical methods. In Section 5 we interpret the empirical results, which are confirmed by the robustness analyses in Section 6 . Conclusions follow (Section 7).

\section{Literature review}

There is an extensive literature on intergenerational support systems. The focus is on downward and upward transfers, where these transfers tend to be divided between the time input family members provide to support each other and transfers in terms of financial support. One key part of time transfers is in the form of childcare. The US literature is rather extensive (e.g., Bass and Caro, 1996; Baydar and Brooks-Gunn, 1998; Fuller-Thomson and Minkler, 2001; Hayslip and Kaminski, 2005; Pebley and Rudkin, 1999; Vandell et al., 2003; Silverstein et al., 2003); the European literature, in contrast, is more limited. A common pattern in all of this literature is that grandparenting is driven by needs, which in turn is motivated by a range of factors including family structure (Douglas and Ferguson, 2003) or financial difficulties (i.e., formal childcare cannot be afforded). Working and younger mothers are more likely to use grand childcare (e.g., Vandell et al., 2003), and Gray (2005) finds that grand childcare is concentrated amongst women without higher education, indicating that informal care is of greatest importance to lower income households. At the same time, the characteristics of the grandparents matter. As suggested by Hagestad (2006), the characteristics of grandparents, parents and children should be considered simultaneously thereby taking a three generation perspective. In old age, grandparents might find it hard to support their children (the parent generation), whereas at a younger age they might themselves be engaged in gainful work. The potentially confounding role of health differentials in the observed associations of childcare with grandparents' age and employment is yet to be fully understood (Hank and Buber, 2009). Grandparenting is also highly gendered. Not surprisingly, grandmothers are more likely to be engaged in childcare than grandfathers, particularly if intensive childcare is required (Gray, 2005; Douglas and Ferguson, 2003; Wheelock and Jones, 2002; Attias-Donfut and Wolff, 2000). Geographic proximity will also matter, and although potentially endogenous, one tends to find that intergenerational support (at least in time transfers) is more extensive if grandparents are living nearby (Ogawa and Ermisch, 1996; Hank and Buber, 2009). However, it is also argued that intergenerational support is not necessarily weakened by geographical mobility (e.g., Litwak, 1960).

There is an important focus on intergenerational support systems in which the role of grandparenting may differ across welfare regimes. Although grandparents play different roles in different regimes, there is little evidence of a general decline in the strength of intergenerational relations (e.g., Hank, 2007; Kohli and Albertini, 2008; Gray, 2005). The literature also stresses the fact that grandparenting is predominantly driven by the needs of the adult children. However, these needs differ substantially across welfare regimes and it is easy to see why it might matter for intergenerational transfers in the form of childcare. In a system that provides broad and universal public childcare (such as the Social Democratic system of the Scandinavian countries), the need for grandparenting is perhaps lower. In contrast, the need for grandparenting might be much stronger in familiastic welfare systems, such as the ones observed in Mediterranean countries. In the former, grandparenting might be seen as a 
way to help parents if in immediate need of assistance. In this sense, grandparents can be seen as a reserve army ready for duty if called upon (Hagestad, 2006). In Mediterranean countries, the nature of grandparenting differs in the sense that they play an integral part of the childrearing duties. Instead of being a reserve army, they are part of the childcare infrastructure of the country. In this sense, grandparents act as child helpers whereas in social democratic countries they act as parent helpers (Hagestad and Herlofson, 2010). These ideas are consistent with empirical evidence. Hank and Buber, 2009 and Albertini et al., 2007, both using the SHARE data, show that the probability of providing care, in general, is higher among Nordic countries and France, whereas it is lower in Mediterranean countries. On the other hand, when Mediterranean grandparents do help in childcare, they do so more regularly and intensively than grandparents in France and the Nordic countries. What lies behind this pattern is that, in Mediterranean countries, parents themselves (essentially, the mother) are the ones who tend to take care of childcare duties. However, if mothers choose to enter the labour force, grandparents very often step in as the prime carers. Such a pattern is consistent with the relatively low levels of labour force participation in these countries, typically around 50 percent in the Mediterranean countries of Italy, Spain, Greece and Portugal, compared to 75 to 80 percent in France and Scandinavian countries. Thus, Mediterranean mothers participating in labour force are in particular need of support through grandparenting - and importantly, grandparenting in those cases tends to be extensive.

While the literature on intergenerational relationships and support is large, the literature concerned with the effects of these transfers on behaviour is much more limited. Many of the existing studies focus on the impact of intergenerational support on mothers' works decisions ${ }^{2}$. Ogawa and Ermisch (1996) assess the impact of intergenerational solidarity on the combination of motherhood and work. They indeed show a positive impact of intergenerational co-residence on female labour force participation, highlighting a clear link between downward time transfers and the work effort of the recipient. Building on this work, a range of studies started focussing on the importance of time transfers from parents to adult children highlighting their positive effect on the participation rates of the latter (Chiuri, 2000; Del Boca, 2002; Bratti, 2003; Marenzi and Pagani, 2008; Arrondel and Masson, 2006; Laferrére and Wolff, 2006; Dimova and Wolff, 2006). Most of these studies are country specific, but they all indicate an important role for intergenerational support in mothers' being able to participate in the labour force. Dimova and Wolff (2006) analyze the impact of private transfers on the career choice of women, taking a comparative perspective. They highlight the fact that grandparenting is potentially endogenous with respect to mothers' behaviour. They argue that financial transfers have limited direct effect on mothers' participation rates, but that grandparenting does play an important role, although the effect is weaker once potential endogeneity is controlled for. Aassve et al. (2011) use the Gender and Generation Survey (GGS) to analyse the impact of grandparenting on mothers' labour force participation in The Netherlands, France, Germany, Romania, Bulgaria, Georgia, Russia and Hungary. The role of grandparenting varies substantially across these countries, but consistent with Hagestad and Herlofson (2010) they find that grandparenting is highly important for families living in countries where grandparenting is less prevalent. Again, the argument is that in those countries where grandparenting is less prevalent, grandparents act as a reserve army for adult children. In other words, they matter in important ways for those few who are in need of support from grandparents. The work of Aassve et al. (2011) also highlights the importance of

\footnotetext{
${ }^{2}$ There is also a literature that concerns the impact of the extended family on younger generations' schooling decisions and schooling outcomes. Loury 2006 finds that the more the parents are educated the better the performance of the children. Also the fact that aunts, uncles, and grandparents attended more years of schooling affects the child's school attendance.
} 
attitudes for intergenerational support and hence their impact on the behaviour of the middle generation, an issue first raised by Guzman (1999). The argument is that in addition to economic and practical needs, attitudes toward childcare also play an important role in explaining time transfers from grandparents. This makes intuitive sense in that grandparents within a given country will necessarily differ in their attitudes towards providing childcare. The actual childcare provided is presumably decided through a negotiation process between the two generations, in which attitudes on either side will affect the outcome.

Given the correlation between female labour force participation and fertility (Mira and Ahn, 2002; Koegel, 2006) and the positive relationship between grandparenting and female labour force participation, it is not implausible to imagine that intergenerational support also matters for fertility behaviour. However, few have considered the impact of grandparenting on fertility behaviour directly. Del Boca (2002) considers the effect of grandparenting on fertility in Italy and finds a positive effect of having one parent alive on both the probability that a woman works and the probability that she had a child in the previous two years. However, actual amount of childcare provided is not observed and the only variation in "grandparents' availability" is captured by the death of last grandparent alive. Hank and Kreyenfeld (2003) estimate the transition risk to first and second births of West German women as a function of the availability of day care in kindergarten but also of informal care provided by the respondent's parents, the latter measured with a dummy for the grandparents living in the same town as their adult children. Their findings suggest that access to informal care arrangements increases the risk of first birth. Similarly Blau and Robins (1989) report that, among employed women, having an additional adult in the household other than the spouse, increases the probability of birth. Lehrer and Kawasaki (1985) show that US women who rely on relatives rather than on paid care providers are more likely to have an additional birth, meaning that grandparenting might reduce the cost of childcare and hence increase fertility. Rindfuss et al. (2007), considering childcare availability and its potential effect on first birth timing in Norway, also study the role of having grandparents living nearby (within the same municipality), the expectation being that it has a positive impact on fertility. However, they find a negative effect at all ages, meaning that the presence or proximity of a potential grandparent is not a sufficient measure to capture actual availability of grandparenting, or that, in a society with near full coverage of public childcare, availability of grandparenting does not have the expected effect.

Whereas grandparenting and fertility is little explored in the literature, the literature concerning formal childcare availability is rather extensive. Much of this literature focuses on the Nordic countries, where high childcare coverage goes in hand with high fertility and female labour force participation. Several studies have suggested that regions with poor childcare coverage have higher fertility (e.g., Kravdal, 1996; Klevmarken and Tasiran, 1996; Rosen, 2004). Anderson et al. (2004), using a multidimensional measure of childcare generosity, also find that Swedish women living in municipalities with poor childcare infrastructure have a higher risk of second births. One possible mechanism is that women tend to speed up the birth of the second child in order to minimize interruptions from the labour market. Thus, their result does not necessarily imply lower overall fertility. However, Rindfuss et al. (2007) using Norwegian data, suggest these results are driven by endogeneity, in the sense that women with strong preferences for children may move to municipalities where childcare coverage is high. Using a fixed effect strategy, they show that high coverage indeed leads to earlier childbearing and that the number of children born is also higher (Rindfuss et al., 2010). Bonoli (2008) takes a similar approach, exploiting variation in family policies across 26 Swiss cantons and their fertility rates. His results suggest that childcare 
availability and child benefits do have positive effects on fertility. Similarly, Del Boca (2002) finds evidence of a positive relationship between availability of public childcare on childbearing in Italy, while Hank and Kreyenfeld (2003) do not find any strong evidence for Germany. In sum, the literature is somewhat mixed, at least when childcare is measured at the community or municipality level.

\section{The methodological framework}

The key interest lies in how adult children's fertility behaviour depends on grandparents' childcare provision. We argue that grandparenting depends on the following key issues. First, some grandparents may be too old or sick, live far away or may not want to sacrifice their leisure time, all of which influence their availability and willingness to help. Secondly, grandparents will have time constraints in the sense that they may not be able to look after all their grandchildren if there are many of them. Thus, if their siblings already have children and are being helped in terms of grandparenting, the adult child lowers their expectation of being helped with childcare by their parents (the children's grandparents). Third, grandparents face energy constraints and may not be able to look after more grandchildren. In particular, the extent of grandparenting will depend on the age of the grandchildren, assuming that taking care of a very young child is more onerous than taking care of older ones.

Using the two waves of SHARE currently available, fertility is in our case measured by whether an adult child has a(nother) child or not between wave one and wave two. The empirical modelling of this process is potentially complex. The key explanatory variable is whether grandparents provide childcare in the first wave, on the assumption that the adult children form expectations about the extent to which they can get help from their parents if they have a(nother) child. This will depend directly on the number of other children that grandparents have (i.e., the number of siblings of the adult child) and the number and the age of their grandchildren. There are consequently a number of different scenarios and the role of grandparenting might differ substantially across them. For some scenarios, we are not able to control directly for grandparenting. For instance, if at the time of the first wave, none of the adult children has children, then grandparenting cannot be observed simply because there are no grandchildren to be taken care of ${ }^{3}$.

Our strategy is to consider three scenarios where we argue that the role of grandparenting might differ and to implement regression analysis separately for each of them. A summary of these scenarios appears in Table 1. In the first scenario, we consider those adult children who already have a child but whose siblings have none. (For simplicity, we use "ego" in the tables to represent the adult child who is the focus of the analysis). In other words, we include all adult children who already have children but have no nieces or nephews, either because they have no siblings or because their siblings have no children. In this case, we observe in the first wave if the adult child is helped by grandparents. We use this information to determine whether those who are helped are more likely to have a second child between wave one and wave two by comparing the fertility behaviour of those helped by grandparents with that of other adult children in the same circumstances, but not helped by grandparents. If grandparents already help at the time of the first interview, it means they are in general

\footnotetext{
${ }^{3}$ In this case, one could make a prediction for their likelihood that the grandparents provide childcare based on their characteristics. This is however a rather heroic out-of-sample prediction, since the prediction has to be based on those who already do provide childcare - and therefore have grandchildren. In earlier specifications, we did construct predicted values for the likelihood of grandparenting. A high value (i.e., likely to provide childcare), was clearly associated with a higher likelihood of entering parenthood for the adult children.
} 
willing to help (denoted "w"). Depending on the age of the grandchild they are looking after, they may have less energy to devote to another young child ("e"). We assume there are no competing constraints on the time ("t") available for grandparenting, either because there are no siblings or the siblings have no children.

Table 1. Three scenarios of parenthood and grandparents' help

\begin{tabular}{llllll}
\hline Scenario & $\begin{array}{l}\text { Ego has } \\
\text { children }\end{array}$ & $\begin{array}{l}\text { Ego's } \\
\text { sibling(s)have } \\
\text { children }\end{array}$ & $\begin{array}{l}\text { Is ego helped } \\
\text { weekly? }\end{array}$ & $\begin{array}{l}\text { Is a sibling } \\
\text { helped weekly? }\end{array}$ & $\begin{array}{l}\text { Constraints on } \\
\text { grandparenting }\end{array}$ \\
\hline 1 & yes & No & Yes & no & w, e \\
2 & no & Yes & No & yes & w, t, e \\
3 & yes & Yes & yes & yes & w, t, e \\
\hline
\end{tabular}

Notes: $\mathrm{w}=$ willingness/availability. $\mathrm{t}=$ time. $\mathrm{e}=$ energy .

The second scenario concerns individuals who are not yet parents, but who already have nieces or nephews, i.e., their siblings have children and thus their parents already have grandchildren. We observe whether the grandparents are helping any of their children with childcare activities at the time of the first wave, and whether an individual whose grandparents help a sibling with childcare is more likely to have their first child between wave one and wave two, compared to other adult children in the same circumstances (i.e. with nieces or nephews, but with no children) but with grandparents not already providing childcare for a sibling. If grandparents already help a sibling at the time of the first interview, this signals willingness $(\mathrm{w})$ to provide childcare. However, they may have less time (t) to look after two grandchildren from two adult children. Depending on the age of the child(ren) already being caring for, the grandparent may have less energy (e) to look after another young child.

In the third scenario, both the focal adult child (ego) and one or more of his/her sibling(s) already have at least one child. This is perhaps the most interesting case, since we can simultaneously observe siblings' fertility behaviours when the grandparenting resource may be particularly scarce. For these adult children and their siblings, we observe whether, and for whom, grandparents are providing help with childcare at the time of the first interview, and determine which adult child is more likely to have another child between wave one and wave two. Here, the grandparenting effect is estimated by exploiting grandparenting and fertility across extended families (as it was in the previous two scenarios) but also within families. As in scenario two, we might observe willingness, time and energy effects at work.

It is useful now to formalize the empirical specification. We start by specifying a model for the focal adult children's fertility decisions as follows.

$$
K_{f i, t}^{*}=\alpha+P_{f i, t-1}^{\prime} \delta+H_{f i, t-1}^{\prime} \varphi+C_{f i}^{\prime} \lambda+\beta G_{f i, t}+\varepsilon_{f i, t} .
$$

$K{ }_{f i, t}$ is a latent variable reflecting propensity for childbearing, in this case to be interpreted as the probability for a child $i$ to have a(nother) baby between wave one and two. If an adult child $i$ from family $f(f i)$ has a child at time $t$, we will observe fertility, $K_{f i, t}=1$ (i.e., the adult child has a new child at time $t$ ) if and only if $K_{f i, t}^{*}>0$. Otherwise, we observe $K_{f i, t}=0$ (no child is born). $P_{f i, t-1}$ is a vector of personal characteristics of the adult child $i$ at time $t-1$. 
$H_{f i, t-1}$ is a vector of characteristics of the household where adult child $i$ lives at time $t-1 . C_{f i}$ is a vector of country level fixed effects which take into account the social and economic context (childcare availability, parental leave arrangements, family allowances, preferences for large families) and $G_{f i, t}$ is the indicator for whether the grandparents provide help for adult child $i$ in family $f$ at time $t$. $\varepsilon_{f i, t}$ is a random error following a logistic distribution.

A key assumption is that, at time $t-1$, each adult child observes his or her parents' grandparenting behaviour and forms expectations about whether they will provide childcare if there is a(nother) child ${ }^{4}$. At time $t$, the adult child may have a(nother) child and our argument is that this depends on their expectation of whether they will receive grandparental help or not. As already noted, we argue that the availability of grandparents in helping adult child $i$ in family $f$ with childcare depends on three factors. This is expressed in the following way: $G_{f i, t}=g\left(w_{f, t} ; t_{f, t} ; e_{f, t}\right)$. First, grandparental help depends on grandparents' availability and willingness to help any of their children (““”) with childcare $\left(w_{f, t}\right)$. Second, grandparents have time constraints $\left(t_{f, t}\right)$. Finally, they might have energy constraints $\left(e_{f, t}\right)$, in the sense that they may not be able to look after more grandchildren (especially if the youngest is very young). Thus, each adult child $i$ who observes $G_{f, t-1}$ will form expectations about the potential help they can get help, $G_{f i, t}$, if a new child is born:

$$
G_{f i, t}=E\left(G_{f, t-1}\right)+s_{f, t}=g\left(w_{f, t-1} ; t_{f, t-1} ; e_{f, t-1}\right)+s_{f, t} .
$$

The interpretation of this equation is that, when grandparents are helping at time $t$ - 1 , each adult child assumes that his or her parents will be able and willing $\left(w_{f, t}\right)$ to help also at time $t$, unless there are some unforeseen shocks that we denote by $s_{f, t}$. These shocks might manifest themselves in terms of a sudden deterioration of grandparents' health, for example. In addition, if the grandparents are already looking after a grandchild from a sibling, which we call $j$, they might not have time to look after a new grandchild from adult child $i$. Even if the grandparents are already looking after a grandchild by a certain adult child $i$, that adult child $i$ might expect that their parents (the grandparents) do not have sufficient energy $\left(e_{f i, t}\right)$ to look after another one.

In our regression analysis, the key explanatory variable is grandparents' childcare activity, which is expressed as $G_{f, t-1}$. Therefore (1) becomes,

$K_{f i, t}^{*}=\alpha+P_{f i, t-1}^{\prime} \delta+H_{f i, t-1}^{\prime} \varphi+C_{f i}^{\prime} \lambda+\beta G_{f, t-1}+\varepsilon_{f i, t}$.

$G_{f, t-1}$ is a dummy variable, grandparents are helping adult child $i\left(G_{f i, t-1}\right)$, in the analysis of scenario 1 , and $G_{f j, t-1}$, grandparents are helping adult child $j$ (a sibling of adult child $i$ ), in the analysis of scenario 2 . Both dummy variables are included in the analysis of scenario 3 . The

\footnotetext{
${ }^{4}$ The adult child might directly ask their parents if they would be able and willing to help in the case of arrival of a newborn child. If this information were available, the model could be modified by inclusion of an error (the difference between what grandparents do and what grandparents say). In our study, however, we can only observe what grandparents do, and then make assumptions about the distribution of the error. This does not affect the rest of the model and interpretation of the results.
} 
reference category is "grandparents not helping anyone" in all three analyses. The analyses are conducted first for the whole relevant sample for each scenario. These scenario-specific sub-samples are further divided by age of the youngest child (under three or three and over) in subsequent analyses to allow us to identify differences in energy constraints when grandchildren are younger or older.

\section{The data}

We use data from SHARE, a multidisciplinary and cross-national panel database of microdata on the health, socio-economic status and social and family networks of more than 45,000 individuals aged 50 or over. The survey is motivated and shares many features of its US cousin - the HRS (Health and Retirement Survey). An important feature of the sampled individuals is that they are asked about their parents, their children, and their grandchildren, allowing us to observe, potentially, four generations at the same time. Personal characteristics concern their health, working status, and their main activities (including childcare). For each of their children, we know age, gender, residence and for - at most - four of them, we have richer information in the form of whether they are in a union, the number of children they have (i.e., the grandchildren of the respondent) and the age of their youngest child, contact frequency with the respondent, and work status and education. Finally, we know how much time the respondents devote to their grandchildren, for each adult child. An important feature of the survey is that it permits use of the respondents' children as the unit of analysis. We measure fertility behaviour across the two waves of the children of the respondents. We select 13,567 households in eleven countries where a person aged 50+ is interviewed in both 2004 and 2006. In 10,353 households, the respondent states s/he has at least one adult child between 20 and 49 years old, which we consider as the fertile age. In 9,753 households, we have personal and family variables for all adult children aged 20-49.

Since the adult children are not the respondents to the survey and hence we do not have a unique identifier for them, we need to match them across the two waves. The matching is based on gender and year of birth. In 8,400 households, all adult children match perfectly between 2004 and 2006. These 8,400 households correspond to 16,691 adult children between 20 and 49 years old. For 16,024 of the adult children, it is possible to have information about their children in both 2004 and 2006 and, therefore, to define the outcome variable, fertility. We provide descriptive statistics in Table 2 for the whole sample of adult children $(16,024)$. However in the analysis we restrict the sample to the adult children belonging to families where grandparents' care is observable in 2004 (i.e. we excluded adult children who in the first wave do not have children and nieces or nephews), and we are left with 10,747 individuals.

With regard to childcare variables, each respondent is asked whether s/he (or they, if in a couple) helps in childcare activities, which of their adult children they help, how frequently and for how many hours a week. In our empirical specification, we consider the dummy variable "help" equal to 1 if the adult child is helped almost every week and is the most helped adult child in terms of hours per week. A small number of grandparents help more than one adult child. In our robustness checks (described in Section 6) we consider how estimates change when grandparents help more than one adult child. Our analytical strategy of focusing on the children of respondents suffers from the limitation that we are only able to capture information about childcare provided by the SHARE respondents, and not by grandparents-inlaw (i.e., the second set of grandparents). Thus, the help of grandparents-in-law represents a potentially important source of unobserved heterogeneity. This issue, and its potential impact on parameter estimates, is discussed in Section 6. 
Table 2: Descriptive statistics of adult children's characteristics

\begin{tabular}{lll}
\hline & Women & Men \\
\hline Proportion of new children born across waves & 0.113 & 0.118 \\
Age & 34.0 & 33.8 \\
In couple (union or marriage) & 0.677 & 0.591 \\
Number of children & 1.06 & 0.82 \\
Years of schooling & 13.1 & 12.9 \\
Work (labour force participation) & 0.708 & 0.841 \\
Living < 25km & 0.679 & 0.700 \\
Any missing variable & 0.009 & 0.007 \\
Austria & 0.068 & 0.063 \\
Germany & 0.069 & 0.072 \\
Sweden & 0.133 & 0.134 \\
The Netherlands & 0.105 & 0.104 \\
Spain & 0.048 & 0.052 \\
Italy & 0.101 & 0.106 \\
France & 0.102 & 0.103 \\
Denmark & 0.064 & 0.060 \\
Switzerland & 0.041 & 0.040 \\
Belgium & 0.148 & 0.146 \\
Greece & 0.122 & 0.121 \\
Observations & 7,849 & 8,175 \\
\hline
\end{tabular}

\section{The results}

Between the two waves, one in nine of the adult children aged between 20 and 49 for whom we have information (Table 2) has a(nother) child. There is little difference between men and women, but women are more likely to be in a couple, to have at least one other child, and to be out of the labour market. Around $70 \%$ of both men and women live relatively close to their parent (by $25 \mathrm{~km}$ ), allowing contact and exchange of care - in the extended family - feasible.

To expand on these descriptive statistics, we estimate a logit regression with random effects for childbearing events across the two waves (Table 3). In this model, no distinction is made for the scenarios described in the previous section. The regression gives a first idea of what matters for fertility and the impact of the control variables. Importantly, the care variables are left out since for several subsamples these cannot be observed. In the same way, we cannot include the age of the children in the household, since not all adult-children already have children. The results are in line with our expectation. Individuals are more likely to have children at a higher age, but at a declining rate. For women, the chances of having another child increases until age 29, whereas for men the turning point is age 32 . Those in unions are considerably more likely to have a child compared to those who are single, and the number of children (at wave one) has a strong negative impact on having another child between the two waves. Currently working is positively associated with childbearing for men, while there is no significant difference between working and non-working women. Education is positively associated with childbearing events, which may be driven by its correlation with income, a variable that cannot be observed in our data. There is no significant effect of geographical proximity. The country differences are also in the expected direction. Greece is here the reference category, and individuals in all other countries are more likely to have another child across the waves. The effect is strongest for Denmark, Sweden and The Netherlands. It is important to remember that the sample is derived as the children of the original respondents in 
SHARE. Thus, individuals may include siblings (if there are brother and sisters), which means that the observations are not necessarily independent of each other. To deal with this we specify a sibling random effect. As is clear from the last line in Table 3, the variation of the sibling specific error component is very small, though the reported rho is statistically significant at the $10 \%$ level.

Table 3: Determinants for having a child - whole sample

\begin{tabular}{|c|c|c|c|}
\hline & Beta & St err & Sig \\
\hline Male & 2.40 & 1.73 & \\
\hline Age & 0.93 & 0.08 & $* * *$ \\
\hline Age*Male & -0.25 & 0.11 & $* *$ \\
\hline Age square & -0.02 & 0.00 & $* * *$ \\
\hline Age square*Male & 0.01 & 0.00 & $* * *$ \\
\hline Couple & 2.06 & 0.12 & $* * *$ \\
\hline Couple*Male & 0.12 & 0.17 & \\
\hline Number of children & -0.46 & 0.05 & $* * *$ \\
\hline Number of children*Male & 0.03 & 0.07 & \\
\hline Years of schooling & 0.03 & 0.02 & $* *$ \\
\hline Years of schooling*Male & -0.01 & 0.02 & \\
\hline Work & 0.08 & 0.10 & \\
\hline Work*Male & 0.51 & 0.18 & $* * *$ \\
\hline Living $<25$ km & 0.01 & 0.09 & \\
\hline Living $<25 \mathrm{~km} *$ Male & -0.19 & 0.12 & \\
\hline Any missing & -0.48 & 0.63 & \\
\hline Any missing*Male & 1.08 & 0.81 & \\
\hline Austria & 1.15 & 0.18 & $* * *$ \\
\hline Germany & 1.44 & 0.17 & $* * *$ \\
\hline Sweden & 1.60 & 0.16 & $* * *$ \\
\hline The Netherlands & 1.57 & 0.16 & $* * *$ \\
\hline Spain & 1.40 & 0.19 & $* * *$ \\
\hline Italy & 1.39 & 0.16 & $* * *$ \\
\hline France & 1.14 & 0.17 & $* * *$ \\
\hline Denmark & 1.69 & 0.17 & $* * *$ \\
\hline Switzerland & 1.22 & 0.20 & $* * *$ \\
\hline $\begin{array}{l}\text { Belgium } \\
\text { (Greece) }\end{array}$ & 1.09 & 0.16 & $* * *$ \\
\hline Constant & -18.05 & 1.313 & $* * *$ \\
\hline Observations & & 16,024 & \\
\hline Rho & & $0.049 *$ & \\
\hline
\end{tabular}

Notes: logit regression with random effects. Significance (Sig) of the estimated coefficients: *** significant at $1 \%, * *$ at $5 \%, *$ at $10 \%$.

Table 4 reports the prevalence of grandparenting across the available countries. The means are calculated from the original SHARE sample of individuals aged 50+ who are grandparents and where the grandchild is aged 14 or younger. We see that helping out on a daily basis in Sweden, Denmark and The Netherlands is not very frequent. This is in contrast to Italy, Greece and Spain, where the prevalence of grandparenting is substantially higher. Not unexpected, the figures are much higher when asked about the prevalence of grandparenting on a weekly basis, although Sweden, Denmark and The Netherlands are still the countries where grandparenting is least frequent. Belgium is interesting in that the daily prevalence is low, but weekly prevalence is as high as Greece and Italy. In the last column of Table 4, we finally observe the percentages of grandparents looking after more grandchildren (younger 
than 14 years old) from two adult-children (i.e., cousins among them): the probability of helping is drastically reduced to about one third. This may suggest that giving childcare support to more adult-children is not easy to handle

Table 4: Grandparents' help with childcare

\begin{tabular}{llll}
\hline Country & Daily & Weekly & $\begin{array}{l}\text { Helping more than one } \\
\text { adult child } \\
\text { (weekly) }\end{array}$ \\
\hline Austria & 0.146 & 0.356 & 0.120 \\
Germany & 0.150 & 0.432 & 0.213 \\
Sweden & 0.029 & 0.214 & 0.046 \\
The Netherlands & 0.023 & 0.429 & 0.184 \\
Spain & 0.243 & 0.375 & 0.163 \\
Italy & 0.331 & 0.476 & 0.174 \\
France & 0.094 & 0.297 & 0.114 \\
Denmark & 0.016 & 0.220 & 0.092 \\
Greece & 0.280 & 0.489 & 0.198 \\
Switzerland & 0.111 & 0.373 & 0.146 \\
Belgium & 0.165 & 0.483 & 0.211 \\
Observations & 3,518 & & 1,502 \\
\hline
\end{tabular}

Notes: statistics on a sample of grandparents with at least one grandchild younger than 14 years old (first two data columns) and on a sample of grandparents with at least two grandchildren younger than 14 years old from two different adult children (third column).

In our empirical analysis to follow, the effect of grandparenting on fertility behaviour is measured in terms of whether the grandparent actually does care for children or not. Before considering the results for the specific scenarios outlined in previous section, it is useful to have a look at the characteristics of those grandparents who actually do perform childcare. In Table 5, we have run two simple logit regressions where the dependent variables are defined over whether they help out daily or not and whether they do it on a weekly basis or not. The results are largely in line with our expectations. First, age is negatively associated with grandparenting. If the grandparent is in a couple, implying that both grandparents are alive, they are more likely to help out on childcare, whereas if the grandparent is still in gainful employment (i.e., working) they are much less likely to help. The indicators for grandparents' physical condition are somewhat mixed. For daily help, most of them are insignificant, and somewhat unexpectedly, those reporting difficulties in standing up from a chair, are more likely to provide childcare. When childcare is measured on a weekly basis, more of these indicators are significant, and they have a negative impact on providing childcare. The country effects are very much in line with Table 4 . The reference category is Greece and we see that grandparents in Scandinavian countries are much less likely to provide childcare. Interestingly, country differences are less pronounced when we consider the estimates for weekly help. 
Table 5: Determinants of grandparents' help with childcare

\begin{tabular}{|c|c|c|c|c|c|c|}
\hline & \multicolumn{3}{|l|}{ Daily } & \multicolumn{3}{|c|}{ Weekly } \\
\hline & Beta & St err & Sig & Beta & St err & Sig \\
\hline Age & -0.03 & 0.01 & $* * *$ & -0.03 & 0.01 & $* * *$ \\
\hline Couple & 0.36 & 0.13 & $* * *$ & 0.47 & 0.09 & $* * *$ \\
\hline At work & -0.44 & 0.15 & $* * *$ & -0.41 & 0.10 & $* * *$ \\
\hline Age of youngest grandchild & -0.02 & 0.02 & & -0.07 & 0.01 & $* * *$ \\
\hline D: walking $100 \mathrm{~m}$ & -0.05 & 0.17 & & -0.29 & 0.13 & $* *$ \\
\hline D: kneeling & -0.06 & 0.13 & & -0.14 & 0.09 & \\
\hline D: pick a coin & -0.27 & 0.23 & & -0.19 & 0.16 & \\
\hline D: climbing stairs & -0.18 & 0.13 & & -0.23 & 0.09 & $* *$ \\
\hline D: climbing one stair & 0.10 & 0.16 & & 0.11 & 0.12 & \\
\hline D: getting up chair & 0.27 & 0.13 & $* *$ & 0.26 & 0.09 & $* * *$ \\
\hline Austria & -0.95 & 0.23 & $* * *$ & -0.72 & 0.19 & $* * *$ \\
\hline Germany & -0.96 & 0.23 & $* * *$ & -0.47 & 0.18 & $* *$ \\
\hline Sweden & -2.61 & 0.29 & $* * *$ & -1.47 & 0.16 & $* * *$ \\
\hline The Netherlands & -2.99 & 0.36 & $* * *$ & -0.55 & 0.16 & $* * *$ \\
\hline Spain & -0.33 & 0.24 & & -0.68 & 0.21 & $* * *$ \\
\hline Italy & 0.13 & 0.17 & & -0.20 & 0.16 & \\
\hline France & -1.46 & 0.22 & $* * *$ & -1.10 & 0.17 & $* * *$ \\
\hline Denmark & -3.28 & 0.52 & $* * *$ & -1.46 & 0.20 & $* * *$ \\
\hline Switzerland & -1.17 & 0.32 & $* * *$ & -0.60 & 0.23 & $* * *$ \\
\hline Belgium & -0.85 & 0.18 & $* * *$ & -0.28 & 0.15 & $*$ \\
\hline (Greece) & 1.21 & 0.64 & $*$ & 2.48 & 0.47 & $* * *$ \\
\hline Observations & 3,518 & & & & & \\
\hline
\end{tabular}

Notes: logit regression on a sample of grandparents with at least one grandchild younger than 14 years old. Significance of the estimated coefficients: *** significant at $1 \%$, ** at $5 \%$, * at $10 \%$. "D:" stands for “difficulty in”.

We now turn, in Table 7, to the estimation of the parameters of interest in the three samples presented previously. Table 7 is divided in three parts: in the upper part we show results from the first sample (adult children who have children but where none of the siblings does); in the middle part results from the second sub-sample (adult children who in the first wave do not have any children but where a sibling does); in the lower part from the third sub-sample (adult children who have children as do their siblings). The coefficients of interest are "ego is helped weekly" (which can be estimated on the first and third sub-sample) and "ego's sibling is helped weekly" (which can be estimated on the second and third sub-sample). All other control variables shown in Table 3 whose effect is significantly different from zero are included, but coefficients are not reported. Table 6 shows the descriptive statistics for the three sub-samples.

Each sub-sample is then further divided in two parts: when the youngest child is younger or older than 3 years old. The assumption we make is that children up to 3 are harder to look after, and the heterogeneity of the results before/after age 3 is then suggestive of the energy effect. The choice of this age as the threshold also allows the two parts of each sub-sample to be of similar and decent sample size. In the first sub-sample we have $39.9 \%$ of adult-children with the youngest child younger than (or equal to) 3 years old, in the second sub-sample $53.2 \%$, in the third sub-sample $28.7 \%$ (looking at the ego's child) and 34.8\% (looking at the sibling's child). One could prefer a lower age threshold for two reasons: first, because the 
probability of having an additional child is higher when the previous one is still young; second, it can better signal the "energy" constraints. However, small sample sizes induce us to divide the sub-samples in this way. In the robustness checks, we will decrease (and increase) the age threshold to see how results may change.

Table 6: Descriptive statistics for sub-samples of adult children

\begin{tabular}{llll}
\hline & \multicolumn{1}{c}{ Sample 1 } & \multicolumn{1}{c}{ Sample 2 } & \multicolumn{1}{c}{ Sample 3 } \\
\hline Newborn child & 0.151 & 0.142 & 0.105 \\
Age & 37.2 & 32.6 & 39.0 \\
In couple (union or marriage) & 0.914 & 0.443 & 0.917 \\
Number of children & 1.75 & 0.00 & 1.98 \\
Age of ego's youngest child & 7.2 & - & 8.6 \\
Age of siblings' youngest child & - & 4.9 & 7.4 \\
Years of schooling & 12.9 & 13.0 & 12.6 \\
Work (labour force participation) & 0.815 & 0.817 & 0.833 \\
Living < 25km & 0.704 & 0.662 & 0.670 \\
Any missing variable & 0.004 & 0.009 & 0.008 \\
Austria & 0.079 & 0.076 & 0.064 \\
Germany & 0.085 & 0.071 & 0.061 \\
Sweden & 0.127 & 0.146 & 0.164 \\
The Netherlands & 0.088 & 0.111 & 0.104 \\
Spain & 0.046 & 0.052 & 0.032 \\
Italy & 0.098 & 0.110 & 0.088 \\
France & 0.109 & 0.104 & 0.113 \\
Denmark & 0.068 & 0.064 & 0.071 \\
Switzerland & 0.038 & 0.037 & 0.031 \\
Belgium & 0.161 & 0.152 & 0.169 \\
Greece & 0.101 & 0.077 & 0.104 \\
Ego helped weekly & 0.313 & & 0.153 \\
Ego's sibling helped weekly & & 0.341 & 0.200 \\
Ego helped weekly (shared) & & & 0.204 \\
Ego's sibling helped weekly (shared) & & & 0.248 \\
No. individuals & 2,869 & 2,908 & \\
No. extended families & & 2,328 & 2,161 \\
\hline & & & \\
\hline
\end{tabular}

Table 7 presents estimates of the key parameter for these three samples. The estimates for sample 1 suggest that there is no impact of grandparenting when the adult child (ego) has no siblings (or has siblings but no nieces or nephews). However, as we will see later, these effects differ dramatically by regions; in particular, when we compare the South European countries with the rest, we find important effects.

In the estimates for sample 2, in contrast, we see that there is a significant reduction in the likelihood of childbearing for the adult child (ego), if the grandparents are already helping one of their siblings with childcare: the probability of having a first child goes from $17.1 \%$ to $14.6 \%$. As already mentioned, we split the sample by the age of the youngest child. The argument is that grandparents are less likely to help, and thus reduce the likelihood of childbearing, if the age of the youngest child they are helping (a sibling's child) is very young. We refer to this as the energy constraint, the idea being that if grandparents are

\footnotetext{
${ }^{5} 59 \%$ of adult children who are already parents in wave one (first and third sub-samples together) and have a new child in wave two, have the first child younger than (or equal to) 2 in wave one; $71 \%$ have the first child younger than (or equal to) 3 in wave one; 78\% have the first child younger than (or equal to) 4 in wave one.
} 
providing childcare to a sibling with a very young child, who presumably is more demanding than an older child, they will have less energy to help out with childcare for the focal adult child (ego) if he or she decides to have a child. However, the differences in estimates are not large, although when the youngest child is older than 3 , the negative impact is no longer statistically significant.

Table 7: Main results

\begin{tabular}{|c|c|c|c|c|c|c|}
\hline \multirow{2}{*}{$\begin{array}{l}\text { SAMPLE } 1 \\
\text { Probability of an additional child }\end{array}$} & \multicolumn{3}{|c|}{ Is ego helped weekly? } & \multicolumn{3}{|c|}{ Is ego's sibling helped weekly? } \\
\hline & Beta & St err & Sig & Beta & St err & Sig \\
\hline Whole sample & -0.164 & 0.133 & & - & & \\
\hline Ego's youngest child $<=3$ & -0.244 & 0.164 & & - & & \\
\hline Ego's youngest child >3 & -0.076 & 0.253 & & - & & \\
\hline SAMPLE 2 & \multicolumn{3}{|c|}{ Is ego helped weekly? } & \multicolumn{3}{|c|}{ Is ego's sibling helped weekly? } \\
\hline Probability of a first child & Beta & St err & Sig & Beta & St err & Sig \\
\hline Whole sample & - & & & -0.332 & 0.132 & $* *$ \\
\hline Sib's youngest child $<=3$ & - & & & -0.359 & 0.168 & $* *$ \\
\hline Sib's youngest child > 3 & - & & & -0.275 & 0.221 & \\
\hline SAMPLE 3 & \multicolumn{3}{|c|}{ Is ego helped weekly? } & \multicolumn{3}{|c|}{ Is ego's sibling helped weekly? } \\
\hline Probability of an additional child & Beta & St err & Sig & Beta & St err & Sig \\
\hline Whole sample & 0.108 & 0.141 & & -0.047 & 0.132 & \\
\hline Ego's youngest child $<=3$ & -0.174 & 0.190 & & -0.225 & 0.176 & \\
\hline Ego's youngest child > 3 & 0.523 & 0.221 & $* *$ & 0.278 & 0.212 & \\
\hline Sib's youngest child $<=3$ & -0.089 & 0.197 & & -0.557 & 0.190 & $* * *$ \\
\hline Sib's youngest child > 3 & 0.343 & 0.208 & $*$ & 0.524 & 0.188 & $* * *$ \\
\hline
\end{tabular}

Notes: logit regressions; all variables whose coefficient is significantly different from zero in Table 3 are included but coefficients are not reported. Significance of the estimated coefficients: *** significant at $1 \%$, ** at $5 \%$, * at $10 \%$.

Each line is a separate regression.

The last section of Table 7 gives the results when both the adult child and a sibling already have children (sample 3) and hence we can observe whether grandparents provide childcare to any of their adult children, and to which one. For the time being, we assume (and impose as a restriction) that only one of the siblings can be helped in grandparenting and, if the grandparents is helping both ego and another sibling, we assume that they are helping only the one who receives the larger number of hours of childcare. In our robustness checks, we relax this restriction in the sense that grandparents may help more than one adult child. In the first line referred to sample 3, we have results for the whole sample of adult children, with no cut by the age of the grandchildren. Both coefficients are not significantly different from zero, hence we do not see any impact of grandparenting on fertility decisions, either ego is the helped child, or when the sibling is the helped child.

When, as before, we make a further cut of the sample by the age of the youngest child, both for ego's children and for siblings' children, we obtain different conclusions. In the second line, where ego has a child younger than 3 the coefficient is insignificant, both if ego is the child helped and if sibling is the child helped. This is in stark contrast to estimates reported in the following line, where the youngest child of ego is older than 3 years of age and ego is the child helped. Now, the impact of receiving help has a strong positive and significant impact on the probability of having another child, which goes from $4.9 \%$ to $6.7 \%$. Interestingly, when a sibling has a child younger than 3 , and grandparents are helping him or her in terms of childcare, the likelihood of childbearing for ego is significantly lower, passing from $16.9 \%$ to 
12.8\%. In the final estimates, reported in the last line of Table 7, the effect of grandparenting is rather different. When a sibling has a child that is older than 3 years of age, and is being helped, ego is 2.1 percentage points more likely to have a child (compared to the average probability of $7.0 \%$ ), which may suggest that grandparents help in turn their adult children in caring for the youngest.

The parameters of Table 7 are re-estimated in Table 8, but now we add the interaction between the variable "weekly care" and the dummy variable "south", which takes the value 1 if the family is in Italy, Greece or Spain, 0 otherwise. The idea behind this set of estimations is that grandparenting appears considerably more important in the South of Europe compared to the rest (see Tables 4 and 5), and might therefore have a more important role for childbearing. Comparing the effect of ego being helped in sample 1 in Table 7 and Table 8 provides striking insights. While being helped has, in general, a negative effect, in the South, receiving help in grandparenting has a strong impact on the likelihood of childbearing, from $20.8 \%$ to $23.9 \%$ if ego has a young child. On the other hand, if ego has a sibling who is helped with a young child and ego lives in South Europe, ego's probability of having an additional child is even lower than in the rest of Europe, going from $12.2 \%$ to $5.3 \%$. Following the hypothesis that grandparents act as parent helpers (Hagestad and Herlofson 2010) in case they are in need, receiving grandparenting is a reflection of hardship in other dimensions surrounding childbearing. Thus, the need for grandparents helping out with childcare signifies family stress, which is negatively associated with having another child.

Table 8: Heterogeneous effects across Europe

\begin{tabular}{|c|c|c|c|c|c|c|}
\hline & \multicolumn{6}{|c|}{ IS EGO HELPED WEEKLY? } \\
\hline SAMPLE 1 & \multicolumn{3}{|c|}{ Is ego helped weekly? } & \multicolumn{3}{|c|}{ Is ego helped weekly?*South } \\
\hline Probability of an additional child & Beta & St err & Sig & Beta & St err & Sig \\
\hline Whole sample & -0.319 & 0.151 & $*$ & 0.745 & 0.326 & $* *$ \\
\hline Ego's youngest child $<=3$ & -0.428 & 0.184 & $* *$ & 0.922 & 0.411 & $* *$ \\
\hline Ego's youngest child >3 & -0.151 & 0.289 & & 0.329 & 0.581 & \\
\hline SAMPLE 3 & \multicolumn{3}{|c|}{ Is ego helped weekly? } & \multicolumn{3}{|c|}{ Is ego helped weekly?*South } \\
\hline Probability of an additional child & Beta & St err & Sig & Beta & St err & Sig \\
\hline Whole sample & 0.086 & 0.155 & & 0.091 & 0.353 & \\
\hline Ego's youngest child $<=3$ & -0.141 & 0.204 & & -0.204 & 0.521 & \\
\hline Ego's youngest child $>3$ & 0.422 & 0.254 & * & 0.403 & 0.506 & \\
\hline Sib's youngest child $<=3$ & -0.013 & 0.217 & & -0.455 & 0.504 & \\
\hline Sib's youngest child > 3 & 0.204 & 0.232 & & 0.767 & 0.518 & \\
\hline & \multicolumn{6}{|c|}{ IS A SIBLING HELPED WEEKLY? } \\
\hline SAMPLE 2 & \multicolumn{3}{|c|}{ Is sibling helped weekly? } & \multicolumn{3}{|c|}{ Is sibling helped weekly?*South } \\
\hline Probability of a first child & Beta & St err & Sig & Beta & St err & Sig \\
\hline Whole sample & -0.366 & 0.151 & $* *$ & 0.145 & 0.309 & \\
\hline Sib's youngest child $<=3$ & -0.379 & 0.187 & $* *$ & 0.101 & 0.421 & \\
\hline Sib's youngest child > 3 & -0.311 & 0.264 & & 0.122 & 0.479 & \\
\hline SAMPLE 3 & \multicolumn{3}{|c|}{ Is sibling helped weekly? } & \multicolumn{3}{|c|}{ Is sibling helped weekly?*South } \\
\hline Probability of an additional child & Beta & St err & Sig & Beta & St err & Sig \\
\hline Whole sample & 0.032 & 0.144 & & -0.473 & 0.361 & \\
\hline Ego's youngest child $<=3$ & -0.114 & 0.191 & & -0.729 & 0.505 & \\
\hline Ego's youngest child > 3 & 0.292 & 0.236 & & -0.033 & 0.526 & \\
\hline Sib's youngest child $<=3$ & -0.367 & 0.206 & $*$ & -1.144 & 0.548 & $* *$ \\
\hline Sib's youngest child > 3 & 0.503 & 0.204 & $* * *$ & 0.183 & 0.511 & \\
\hline
\end{tabular}

Notes: logit regressions; all variables - whose coefficient is significantly different from zero in Table 3 - are included but coefficients are not reported. Significance of the estimated coefficients: *** significant at $1 \%, * *$ at $5 \%$, * at $10 \%$. 


\section{Robustness checks}

It is worthwhile providing robustness checks to the results that were presented above. We reestimate the model by changing one by one certain aspects that might influence the estimates. These results are presented in Tables 9A and 9B. Starting with Table 9A, we present in the first column the same results as presented in Table 7 . We first select only adult children in couples (column (a)), we change the age threshold for the youngest child, respectively, to age 2 and 4 (columns (b) and (c)), we then consider as main independent variable "daily care" instead of "weekly care" (column (d)), and finally we include in the analyses only adult children living close to the respondent grandparent (column (e)). The first important thing to notice is that they do seem very close to the original ones ${ }^{6}$.

Table 9A: Robustness checks I

\begin{tabular}{|c|c|c|c|c|c|c|}
\hline & Table 7 & Couple (a) & Two (b) & Four (c) & Daily (d) & Close (e) \\
\hline \multicolumn{7}{|l|}{ Sample 1 - Ego is helped } \\
\hline Whole sample & -0.164 & -0.170 & -0.164 & -0.164 & -0.172 & -0.243 \\
\hline Ego's youngest child $<=3$ & -0.244 & -0.250 & $-0.397 * *$ & -0.207 & -0.350 & $-0.362 *$ \\
\hline Ego's youngest child $>3$ & -0.075 & -0.119 & 0.042 & 0.113 & 0.074 & -0.194 \\
\hline \multicolumn{7}{|c|}{ Sample 2 - Ego's sibling is helped } \\
\hline Whole sample & $-0.332 * *$ & $-0.367 * *$ & $-0.332 * *$ & $-0.332 * *$ & -0.244 & $-0.405^{* *}$ \\
\hline Sib's youngest child <= 3 & $-0.359 * *$ & -0.316 & $-0.323 *$ & $-0.316^{* *}$ & -0.274 & -0.356 \\
\hline Sib's youngest child $>3$ & -0.275 & $-0.460 *$ & $-0.360 *$ & -0.411 & -0.213 & -0.478 \\
\hline \multicolumn{7}{|l|}{ Sample 3 - Ego is helped } \\
\hline Whole sample & 0.108 & 0.098 & 0.108 & 0.108 & -0.103 & 0.160 \\
\hline Ego's youngest child $<=3$ & -0.174 & -0.191 & -0.14 & -0.153 & -0.547 & -0.142 \\
\hline Ego's youngest child $>3$ & $0.523^{* *}$ & $0.551 * *$ & 0.316 & $0.706 * * *$ & 0.463 & $0.537 * *$ \\
\hline Sib's youngest child <= 3 & -0.089 & -0.143 & -0.080 & -0.002 & -0.069 & -0.205 \\
\hline Sib's youngest child $>3$ & $0.343^{*}$ & $0.383^{*}$ & 0.283 & 0.264 & -0.101 & $0.470 * *$ \\
\hline \multicolumn{7}{|c|}{ Sample 3 - Ego's sibling is helped } \\
\hline Whole sample & -0.047 & -0.130 & -0.047 & -0.047 & -0.227 & -0.051 \\
\hline Ego's youngest child $<=3$ & -0.225 & -0.24 & -0.227 & -0.174 & -0.367 & -0.328 \\
\hline Ego's youngest child $>3$ & 0.278 & 0.143 & 0.142 & 0.187 & 0.129 & 0.385 \\
\hline Sib's youngest child $<=3$ & $-0.557 * * *$ & $-0.621 * * *$ & $-0.434 * *$ & $-0.412 * *$ & $-0.843 * *$ & $-0.829 * * *$ \\
\hline Sib's youngest child $>3$ & $0.524 * * *$ & $0.415^{* *}$ & 0.241 & $0.513 * *$ & 0.347 & $0.741^{* * *}$ \\
\hline
\end{tabular}

Notes: coefficients from similar regressions as in Table 7 but a) including in the sample only individuals in couples, b) where the age threshold for the child is set to 2 instead of 3, c) where the age threshold for the child is set to 4 instead of 3, d) including daily care instead of weekly, e) selecting only adult-children living - at most $-25 \mathrm{~km}$ far away from their parents.

The most striking difference is the low significance of the results when we include "daily" instead of "weekly", nevertheless the direction and the size of the coefficients are rather close. We think that this may be the consequence of the low variability of the daily variable compared to the weekly one, as can easily seen in Table 4. Furthermore, daily care is very country-specific and, since we include the country-dummies in the model, there is little variability to exploit which can make our estimator not very powerful.

Results concerning the effect of "Sibling is helped" in the second sample (adult children without children and with siblings with children) are all negative but not homogenously significant. As we already commented in the main results, the effect does not seem to differ

\footnotetext{
${ }^{6}$ We test whether each new coefficient (columns (a) - (e)) is significantly different from the original one (first column) and always accept the null hypothesis that they are not different.
} 
by the age of the youngest child, supporting the time more than the energy explanation in this scenario.

When looking at the effects of ego/sibling being helped in sample 3, results are fairly robust, with exception of the model with 2 as age threshold for the youngest child. When ego's (or a sibling's) youngest child is older than 2, coefficients lose significance. This suggests that, in this case, it would be still tiring for grandparents looking after a new very young child.

When we exclude from the samples adult children living more than $25 \mathrm{~km}$ from the respondent grandparent (around 30\% of our samples), we find larger effects (both positive and negative), indicating that adult children living close are the ones most influenced by grandparents' help.

Finally, in Table 9B we present further robustness checks for sample 3, for which we can include random effects (column (f)), and we relax the assumption that grandparents are helping only one adult-child (column (g)). When we include a random effect control for sibling pairs, the estimates are also rather robust (column (f) $)^{7}$.

Table 9B: Robustness checks II

\begin{tabular}{llll}
\hline & Table 7 & RE (f) & Shared (g) \\
\hline Sample 3 - Ego is helped & & & \\
Whole sample & 0.108 & 0.119 & 0.021 \\
Ego's youngest child $<=3$ & -0.174 & -0.171 & -0.118 \\
Ego's youngest child $>3$ & $0.523^{* *}$ & $0.531^{* *}$ & 0.268 \\
Sib's youngest child $<=3$ & -0.089 & -0.084 & -0.089 \\
Sib's youngest child $>3$ & $0.343^{*}$ & $0.343^{*}$ & 0.170 \\
Sample 3 - Ego's sibling is helped & & & \\
Whole sample & -0.047 & -0.042 & -0.022 \\
Ego's youngest child $<=3$ & -0.225 & -0.227 & -0.181 \\
Ego's youngest child $>3$ & 0.278 & 0.285 & 0.272 \\
Sib's youngest child $<=3$ & $-0.557^{* * *}$ & $-0.577^{* * *}$ & $-0.438^{* * *}$ \\
Sib's youngest child $>3$ & $0.524^{* * *}$ & $0.524^{* * *}$ & $0.456^{* * *}$ \\
\hline Notes: coefici
\end{tabular}

Notes: coefficients from similar regressions as in Table 7 but f) with random effects, g) when more adultchildren may be helped by grandparents at the same time.

So far, we have also imposed the restriction that grandparents can only help either ego or a sibling. Thus, the meaning of "Being helped" was "being the most helped adult child, in terms of hours a week, among adult children helped weekly". This implies that, for each extended family, the variable "Ego (or ego's sibling) is helped" could be equal to one only for one of the adult-children. In column (f) of Table 9B, estimation is done again relaxing this restriction, meaning that the dummy variable "Ego is helped" can be equal to one for more than one adult-child. The effects are statistically not different but smaller in magnitude, meaning that being the one most helped makes some difference.

Despite the encouraging results from the robustness checks, one should bear in mind caveats that cannot easily be solved with our dataset. There are for instance several omitted variables

\footnotetext{
${ }^{7}$ We also tried to estimate a fixed effect logit model, which is similar to estimating the commonly used siblingestimator. But the FE logit only includes those observations where childbearing events took place. The sample size would consequently be dramatically reduced (200 extended families).
} 
that may have an impact on the estimated relationships. Whereas we find a robust positive relationship between grandparents' help and fertility, it may be the case that grandparents help those of their adult children with the strongest and revealed preferences for fertility.

Alternatively, they may help the poorest adult child, who cannot afford private childcare, but might have stronger preferences for a large number of children. Grandparenting might also be driven by exchange in the sense that grandparents are more likely to help the adult child from whom they themselves receive most help. There may also be a bias, unobserved in our study, if both parties have a stronger preference for large families.

Moreover, we only observe one side of the extended family. We do not know whether grandparents-in-law are helping or not. How would this affect our results? We can think about three scenarios. Assume a first scenario where there is no correlation between grandparents' help and grandparents-in-law help. In this case there would not be any bias. Assume instead a second scenario where grandparents are not helping the adult child because he or she is already helped by the grandparents-in-law, which would imply a negative correlation. This would leave us with a downward bias, which would make our estimates conservative. If instead we consider a positive correlation, which would mean that the grandparents help more as the grandparents-in-law also help, one would get an upward bias. This is of course possible and would happen if the adult child is in a couple where both have strong family ties. In this case, our estimates would refer to the joint impact of grandparenting of both sets of grandparents. Of course, this does not alter the conclusions of the analysis: Grandparents' childcare (one or two-sided) does influence fertility.

Finally, our data are representative for the original 50+ grandparents, not for their adult children who are taken as the unit of the analysis. Our sample suffers therefore from a potential "longevity" selection in the sense that we tend to observe grandparents that are in better health than the population average. In order to have an idea of how relevant the sample selection is, we can use other data (representative of the general population) where we can observe what percentage of adults 20-49 years old (that would correspond to our "adult children") have at least one parent alive (that would correspond to our "respondent grandparents"). We use the Gender and Generation Survey for France, Germany, the Netherlands and the Survey "Family and Social Subjects for Italy" for Italy, where we have information about parents alive. We find that $93 \%$ of adults in Germany and Italy have at least one parent alive, $92 \%$ in the Netherlands, and 94\% in France. The average age of adults in these samples are, respectively, 36, 35, 36, and 35. These adults are slightly older than the ones in our sample (34, see Table 2$)$.

\section{Conclusions}

Our analysis shows rather robust evidence that grandparenting plays an important role in adults' childbearing decisions. If siblings are already helped by grandparents then this has a negative impact on the childbearing decision. The effect is independent of whether we are considering individuals potentially entering parenthood or progressing from a higher parity. It also seems clear that willingness, time constraints and energy constraints matter, which supports the notion that grandparents as childcare providers are a scarce resource that has to be shared and potentially be competed for among siblings. Another significant finding although not unexpected - is that the importance of grandparenting for childbearing decisions is much greater in the Mediterranean countries where welfare support, particularly in terms of public childcare, is much weaker. These results are very much in line with Hagestad (2006) and Hagestad and Herlofson (2010) who argue that in Nordic countries the role of 
grandparents is to help out their adult children in case of need - a reserve army of childminders ready to step in if the need arises. Our analysis suggests that grandparenting in Nordic countries is a sign of family stress, which is followed by a lower likelihood of having another child. Instead, in societies where grandparents are an integral part of the childcare infrastructure, grandparenting fosters childbearing.

Our findings have implications for a wide range of issues. First, compared to a system where childcare provision is institutionalized outside the family sphere, grandparenting is potentially a source of inequality in the sense that those who have access to grandparenting are more able to realize their fertility desires. In contrast, for those adult children whose grandparents are ill or frail the chances are lower. Secondly, grandparents have capacity constraints and are thus a scarce resource that may restrain people from achieving higher parity births. There is also some indication that energy constraints matter in the sense that grandparents are less likely to provide more childcare when they already have very young grandchildren. This means in most cases that the mothers themselves are the ones taking care of children when very young. In turn, this will affect the time they have to stay out of the labour market following childbirth.

\section{Acknowledgement}

Research funding from the ERC (StG-201194) is gratefully acknowledged.

\section{References}

Aassve, A., B. Arpino and A. Goisis. 2011. "Grandparenting and mothers' employment: a comparative perspective". Dondena Working paper, No. 36.

Albertini, M., M. Kohli and C. Vogel 2007. "Intergenerational transfers of time and money in European families: Common patterns - different regimes?” Journal of European Social Policy 17(4): 319-334.

Andersson, G., A.Z. Duvander and K. Hank. 2004. "Do childcare characteristics influence continued childbearing in Sweden? An investigation of the quantity, quality and price dimension.” Journal of European Social Policy 14(4): 407-418.

Arpino, B., Pronzato C.D., Tavares L. 2010. "All in the Family: Informal Childcare and Mothers’ Labour Market Participation.” ISER Working Paper Series, 2010-24.

Arrondel, L. and A. Masson. 2006. "Altruism, exchange or indirect reciprocity: what do the data on family transfers show?” In: S.C. Kolm \& J. Mercier Ythier (Eds.). Handbook on the Economics of Giving, Reciprocity and Altruism. North-Holland: Elsevier: pp. 971-105

Attias-Donfut, C. and F. Wolff. 2000. “The redistributive effects of generational transfers.” Arber S., Attias-Donfut C., eds .The myth of generational conflict. The family and state in ageing societies. Routledge, London: pp. 22-46.

Bass, S.A. and F.G. Caro. 1996. "The economic value of grandparent assistance.” Generations 20(1): 29-33.

Baydar, N. and J. Brooks-Gunn. 1998. "Profiles of grandmothers who help care for their grandchildren in the United States.” Family Relations 47(4): 385-93.

Blau, D.M. and P.K. Robins 1989. "Fertility, employment and child-care costs.” Demography 26(2): 287-299.

Bonoli, G. (2008). “The impact of social policy on fertility: evidence from Switzerland.” Journal of European Social Policy 18(1): 64-78 
Bratti, M. 2003. "Female Labour Force Participation and Marital Fertility of Italian Women: The Role of Education.” Journal of Population Economics 16(3): 525-554.

Chiuri, M.C. 2000. "Quality and demand of child care and female labour supply in Italy.” In: Del Boca D., Tanda P. (eds.) Labour. Special Issue on Household behavior and Social Policies.

Del Boca, D. 2002. "The Effect of child care on participation and fertility." Journal of Population Economics 15( 3): 549-573.

Dimova, R. and F.C. Wolff. 2006. "Do downward private transfers enhance maternal labor supply? Evidence from around Europe.” IZA Discussion Papers 2469, Institute for the Study of Labor (IZA).

Douglas, G. and N. Ferguson. 2003. "The role of grandparents in divorced families.” International Journal of Law, Policy and the Family 17(1): 41-67.

Fuller-Thomson, E. and M. Minkler. 2001. "American grandparents providing extensive child care to their grandchildren: prevalence and profile.” The Gerontologist 41(2): 201-9.

Gray, A. 2005. "The changing availability of grandparents as carers and its implications for childcare policy in the UK.” Journal of Social Policy 34(4): 557-577.

Guzman, L. 1999. “The use of grandparents as child care provides”. NSFH Working Paper No. 84. Centre for Demography and Ecology, University of Wisconsin-Madison

Hagestad, G.O. 2006. "Transfers between grandparents and grandchildren: The importance of taking a three-generation perspective.” Zeitschrift für Familienforschung, pp. 315-332.

Hagestad, G.O. and Herlofson, K. 2010. "Transformations in the role of grandparents across welfare states.” Paper presented at the XVII ISA World Congress of Sociology, Gothenburg, 11-17 July.

Hank, K. 2007. "Proximity and contacts between older parents and their children: A European comparison." Journal of Marriage and Family 69 (1): 157-173.

Hank, K. and I. Buber. 2009. "Grandparents caring for grandchildren: Findings from the 2004 Survey of Health, Ageing and Retirement in Europe.” Journal of Family Issues 30(1): 53-73.

Hank, K. and M. Kreyenfeld. 2003. "A multilevel analysis of child care and women's fertility decisions in West Germany.” Journal of marriage and the family 65(3): 584-596.

Hayslip, B. and P.L. Kaminski. 2005. "Grandparents raising their grandchildren: A review of the literature and suggestions for practice.” The Gerontologist 45(2): 262-269

Klevmarken, N.A. and A.C. Tasiran. 1996. "Is the decision 'to work' endogenous to the fertility process?” Memorandum 220, Gothenburg University

Knudsen, L.B. and M. Murphy. 2002. "The intergenerational transmission of fertility in contemporary Denmark: the effects of number of siblings (full and half), birth order, and whether male or female.” Population Studies 56(3): 235-248.

Koegel, T. 2006. "An explanation of the positive correlation between fertility and female employment across Western European countries.” Discussion Paper Series 2006_11, Department of Economics, Loughborough University.

Kohli, M. and M. Albertini. 2008. "The family as a source of support for adult children's own family projects: European varieties.” In Families, Ageing and Social Policy.

Intergenerational solidarity in European Welfare States, CHELTENHAM, Edward Elgar, pp. 38 - 58 (Globalization and Welfare).

Kravdal, Ø. 1996. "How the local supply of day-care centers influences fertility in Norway: A parity-specific approach.” Population Research and Policy Review 15(3): 201-218

Laferrère, A. and F.C. Wolff. 2006. "Microeconomic models of family transfers.” In: Mercier, J., Ythier, Kolm, S.C. (Eds.), Handbook on the Economics of Giving, Reciprocity and Altruism, North-Holland. 
Lehrer, E. and S. Kawasaki. 1985. "Childcare arrangements and fertility: an analysis of twoearner households.” Demography 22(4): 499-513.

Litwak, E. 1960. "Geographic mobility and extended family cohesion.” American Sociological Review 25(3): 385-394.

Loury, L. 2006. "All in the Extended Family: Effects of Grandparents, Aunts, and Uncles on Educational Attainment," American Economic Review96(2): 275-278,

Marenzi, A. and L. Pagani. 2008. "The labor market participation of sandwich generation Italian women.” Journal of Family and Economic Issues 29(3): 427-444.

Mira, P. and N. Ahn. 2002. "A note on the changing relationship between fertility and female employment rates in developed countries.” Journal of Population Economics 15(4): 667-682.

Ogawa, N. and J. F. Ermisch. 1996. "Family structure, home time demands, and the employment patterns of Japanese married women. ” Journal of Labor Economics 14(4): 677-702.

Pebley, A.R. and L.L. Rudkin. 1999. "Grandparents caring for grandchildren. What do we know?”. Journal of Family Issues 20(2): 218-242.

Rindfuss, R.R., D.K. Guilkey, S.P. Morgan and O. Kravdal. 2010. "Child-care availability and fertility in Norway." Population and development review 36(4): 725-748.

Rindfuss R.R., D.K. Guilkey, S.P. Morgan, O. Kravdal and K.B. Guzzo. 2007. "Child-care availability and first-birth timing in Norway.” Demography 44(2): 345-372.

Rosen, M. 2004. "Fertility and public policies- Evidence from Norway and Finland.” Demographic Research 10(6): 143-170.

Silverstein, M., R. Giarruso and V. Bengtson. 2003. "Grandparents and grandchildren in family systems. A socio-development perspective. In V. Bengtson and A. Lowenstein (Eds.). Global Aging and Challenges to Family. New York: Aldine de Gruyter, 75102.

Vandell, D., K. McCartney, M. Owen, C. Booth and A. Clarke-Stew. 2003. "Variations in child care by grandparents during the first three years." Journal of Marriage and the Family 65(2): 375-381

Wheelock, J. and K. Jones. 2002. "Grandparents are the next best thing: Informal childcare for working parents in urban Britain.” Journal of Social Policy 31(3): 441-463. 